\title{
Adaptive droop control for better current-sharing in VSC-based MVDC railway electrification system
}

\author{
Salman AATIF ${ }^{1}$, Haitao HU ${ }^{1}$, Xiaowei YANG ${ }^{1}$, Yinbo GE ${ }^{1}$, \\ Zhengyou HE ${ }^{1}$, Shibin GAO ${ }^{1,2}$
}

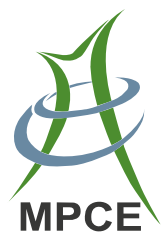

\begin{abstract}
The share of voltage source converter (VSC) technology is increasing in conventional power systems, and it is penetrating into specific transportation systems such as electric vehicles, railways, and ships. Researchers are identifying feasible methods to improve the performance of railway electrification systems (RESs) by utilizing VSC-based medium-voltage direct current (MVDC) railways. The continuous motion of electric trains makes the catenary resistance a variable quantity, as compared to the traction substation (TSS), and affects the currentsharing behavior of the system. A modified droop control technique is proposed in this paper for VSC-based MVDC RES to provide more effective current-sharing while
\end{abstract}

CrossCheck date: 25 September 2018

Received: 19 May 2018/Accepted: 26 September 2018/Published online: 3 January 2019

(C) The Author(s) 2019

$\triangle$ Shibin GAO

gao_shi_bin@126.com

Salman AATIF

salmanatif@uetpeshawar.edu.pk

Haitao HU

hht@swjtu.edu.cn

Xiaowei YANG

yxwswjtu@163.com

Yinbo GE

gyb_good@163.com

Zhengyou HE

hezy@swjtu.edu.cn

1 College of Electrical Engineering, Southwest Jiaotong University, Chengdu, China

2 National Rail Transit Electrification and Automation Engineering Technique Research Center, Southwest Jiaotong University, Chengdu, China maintaining catenary voltages above the minimum allowable limit. The droop coefficient is selected through an exponential function based on the ratio between the concerned TSS current and the system average current. This enables small adjustments of droop values in less concerning marginal current deviations, and provides higher droop adjustments for large current deviations. Meanwhile, the catenary voltages are regulated by considering the voltage data at the midpoint between two TSSs, which experiences the lowest voltages owing to the larger distance from the TSSs. The proposed techniques are validated via simulations and experiments.

Keywords Railway electrification, Voltage source converter (VSC), Medium-voltage direct current (MVDC), Current sharing, Renewable energies in railways

\section{Introduction}

In recent years, the railway transportation system has become a rapid and reliable means of traveling. Old fossilfueled railway systems have been replaced with new highly sophisticated electric railways, owing to their higher performance, less energy costs, and environmentally friendly profile [1]. The AC electrification system is widely used in high power, high-speed corridors worldwide owing to its convenient transformation at high voltages $(15-25 \mathrm{kV})$. Meanwhile, the DC electrification system is generally utilized in low power trains such as trams, metros, and suburban railways, with voltages ranging from $600 \mathrm{~V}$ to $3 \mathrm{kV}$, because of its complex voltage transformation system [2]. Notwithstanding the numerous advantages of the AC railway electrification system (RES), it exhibits certain challenges including voltage and current distortions owing to 
harmonics generated by the traction load of trains and the capacitive and inductive effects of catenary [3, 4]. However, advancements in the fields of power electronics and voltage source converter (VSC) technology have enabled engineers to consider DC transmission for long distances at high voltages in conventional power systems. The focus is mainly on the North Sea countries, where the plan is to transmit $100 \mathrm{GW}$ of energy from offshore sites into the mainland [5]. Practical examples of such VSC-high voltage direct current (VSC-HVDC) transmission lines are the $320 \mathrm{kV}$ HVDC system between Spain and France, and the 420 and $500 \mathrm{kV}$ systems in China [6].

After the successful implementation of VSC-HVDC transmission systems for conventional power grids, there is increasing interest toward considering the application of this technology in the field of RES for high-speed railways. A few articles have considered the use of modular multilevel converters (MMCs) for catenary voltage stabilization [7-10]. Certain fundamental concepts and the framework of the VSC-based medium-voltage direct current (MVDC) RES for high-speed railways are available in [2, 11-13]. Such MVDC systems consist of several VSC-based traction substations (TSSs) along the catenary line, providing energy to the system according to the requirement of the train loads. The catenary becomes a continuous network without neutral sections. Moreover, the VSC TSSs consume electricity from the main high voltage feeders as well as from renewable energy sources such as wind turbines, photovoltaic (PV) stations, and energy storage systems distributed along the traction line. Thereby, the whole RES becomes an MVDC grid in which each VSC-based substation contributes its share of power to the system.

Controlling such an MVDC railway grid is similar to controlling a conventional DC microgrid. In RES, the train load is continuously moving along the traction line and is changing its position; this makes the traction line resistance between the VSC TSS and train loads a variable quantity. Because of the variable traction line resistance, the VSC TSS near a train experiences less traction line resistance and contributes more power to the system as compared to the ones at a distance from the train. This behavior can overload renewable energy TSSs and take stiff grid connected TSSs to their maximum limits [11]. The conventional droop control technique improves the currentsharing behavior of the VSC TSS; however, it generates larger voltage deviations in the catenary network (its simulation is described in the next section). Different authors have devised improvements in the droop control technique for more effective current-sharing in conventional DC microgrids. A few of them will be discussed in the next section.

In this paper, a modified droop control technique is proposed to improve the current-sharing capability of the
VSC TSSs while maintaining the catenary voltage deviation above its minimum allowable limits. The major contributions of the paper can be summarized as follows:

1) Analysis of the effects of the dynamic traction line resistances caused by moving train loads, on the current-sharing behavior of VSC TSSs; analysis of the catenary voltage deviation caused by the conventional droop.

2) An improved droop control scheme is proposed, which enhances the current-sharing behavior of VSC TSSs by selecting a droop coefficient using the TSSs current ratios and an exponential function. This is achieved without compromising on the maximum permitted deviation in the voltage at critical points along the catenary.

\section{VSC-based MVDC RES}

The general layout, advantages, and basic control of such a system is presented in $[2,11]$. This paper is more related to the control technique for more effective currentsharing in similar MVDC-RES environments. For the convenience of readers, the system is described in the preceding subsections.

\subsection{System topology}

The general architecture of the system is provided in Fig. 1. As the system is DC-based, there is no reactance in the catenary network; this results in less voltage drops, lower energy demands, and less requirement of TSSs for a specific line as compared to the current AC RES. In addition, it eliminates the problem of harmonic distortion,

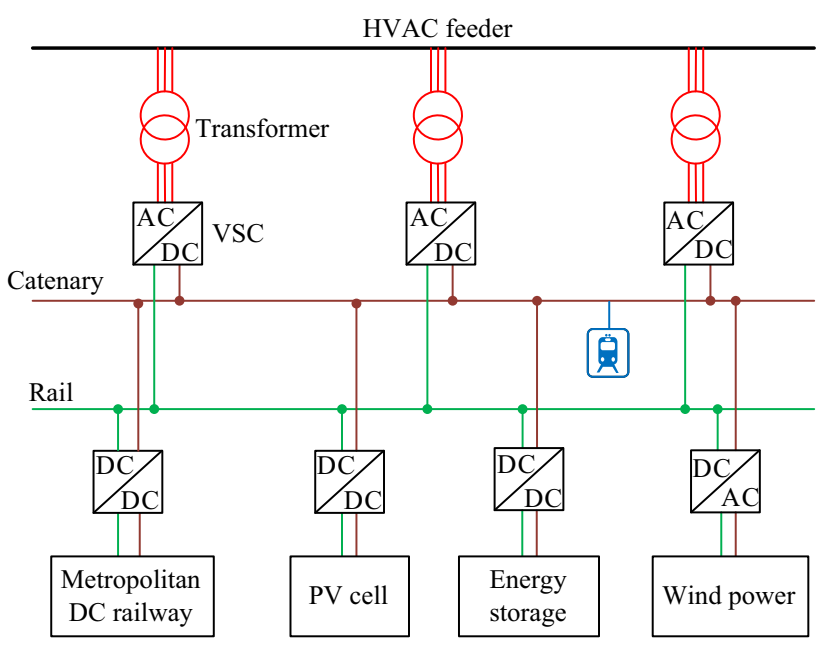

Fig. 1 General architecture of VSC-based MVDC RES 
and the system becomes devoid of power factor constraints.

Renewable energies can conveniently be integrated to the RES with the aid of AC/DC and DC/DC converter modules. Energy storage facilities along the traction line can store the surplus energy, as well as energy from the braking system [14-16], which can be utilized by accelerating trains or can also be shared with metropolitan DC railways. Although [2] provides brief information about the basic architecture, advantages, and control of the system, in simulations, equally-spaced trains are considered on the traction line; this is the best-case scenario for a droop control scheme, as each VSC TSS encounters a similar traction line resistance and shares an equal amount of power to the system (simulated in Section 5).

Practically, trains are not always equally spaced, and the train timetables are mostly managed according to the density of the passengers. Unequally-spaced trains with respect to stationary TSSs causes unequal traction line resistance between the VSC TSSs and train loads. This creates a current-sharing unbalance, and the system drags more current from the VSC TSS located near to the loads than from those at a distance from the loads. The effects of catenary resistance on the load-sharing behavior are explained in the next sub-section.

\subsection{Effects of variable traction line resistance under conventional droop control scheme}

To better understand and quantify the impacts of the traction line resistance on the current-sharing capabilities of the sources, we will consider an example of a train moving between two TSSs (TSS\#1 and TSS\#2), which are $100 \mathrm{~km}$ apart. A simplified equivalent circuit is shown in Fig. 2. Here, $R_{\text {droop } 1}$ and $R_{\text {droop } 2}$ are the droop values of TSS\#1 and TSS\#2, respectively, where $R_{1}$ is the traction line resistance between TSS\#1 and the train; $R_{2}$ is the traction line resistance between TSS\#2 and the train. Considering the standard traction line resistance mentioned in Table 1, a traction line resistance of $0.1318 \Omega / \mathrm{km}$ is obtained through (1) by considering the resistance of the contact and messenger wire to be in parallel and the rail resistance to be in series with this combination:

$R_{T}=\left(\frac{R_{c} R_{m}}{R_{c}+R_{m}}\right)+R_{r}$

If both the TSSs have an equal droop value $\left(R_{\text {droop } 1}=R_{\text {droop } 2}=1 \Omega\right)$ and equal terminal voltage, an equal current-sharing can be guaranteed if both the TSSs encounter an identical traction line resistance ( $R_{1}=R_{2}=R_{\text {avg }}$ ) where $R_{\text {avg }}$ is the average value of the

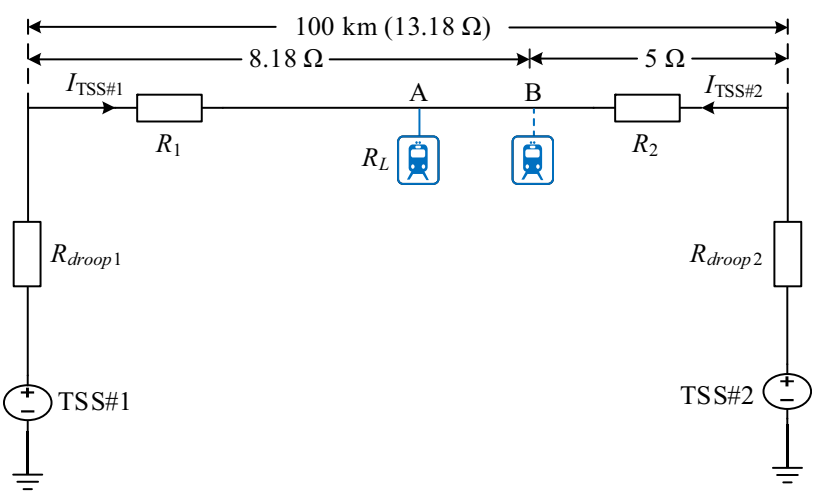

Fig. 2 Change in traction line resistance owing to motion of train from TSS\#1 to TSS\#2

Table 1 Resistances of wires and rails

\begin{tabular}{lll}
\hline Parameter & Type & Value $(\Omega / \mathrm{km})$ \\
\hline Resistance of contact wire $\left(R_{c}\right)$ & CTMH150 & 0.2420 \\
Resistance of messenger wire $\left(R_{m}\right)$ & JTMH120 & 0.1840 \\
Resistance of rail $\left(R_{r}\right)$ & P60 & 0.0273 \\
Traction line resistance $\left(R_{T}\right)$ & - & 0.1318 \\
\hline
\end{tabular}

traction line resistance between the train load and TSSs and can be calculated as

$R_{\mathrm{avg}}=\left(R_{1}+R_{2}\right) / 2$

The condition of equal current-sharing can be satisfied if the train reaches the midpoint between the two TSSs, i.e., point A. At this point, $R_{\mathrm{avg}}=6.59 \Omega$. If the train continues to move and reaches point $\mathrm{B}, R_{1}$ becomes $8.18 \Omega$, whereas $R_{2}$ becomes $5 \Omega$. At point $\mathrm{B}$, the train draws more current from TSS\#2 as compared to TSS\#1.

Hence, changes in traction line resistance due to continuous motion of the train disrupt the ideal current-sharing property of the system. It is also noteworthy that the maximum voltage deviation owing to the cumulative effect of the traction line resistance and increase in the droop value occurs at point $\mathrm{A}$, as it is the midpoint between the two TSSs. In this paper, we will use the term critical point voltage (CPV) for the voltages at these midpoints between TSSs.

By considering the journey of a train on a $300 \mathrm{~km}$ traction line having three TSSs as shown in Fig. 3, the current-sharing enhancement through the conventional droop and its effect on the catenary voltage is explained through the simulation results in Figs. 4 and 5, respectively. Each TSS consists of a step-down transformer and a three-level VSC, each having identical power rating of 


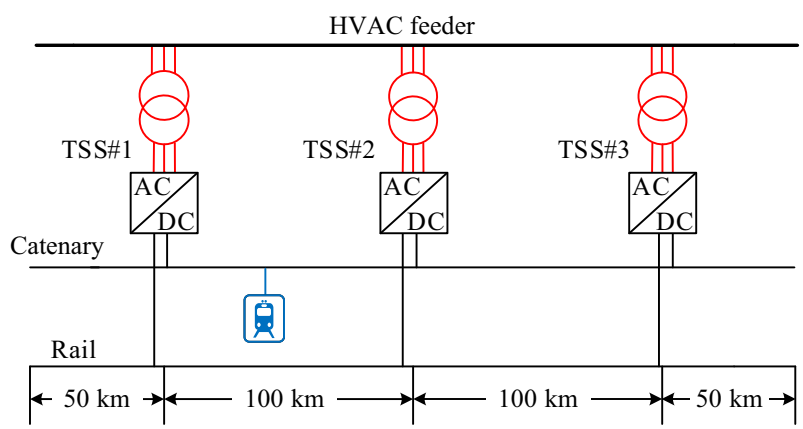

Fig. 3 Layout of a $300 \mathrm{~km}$ line comprising three VSC TSSs

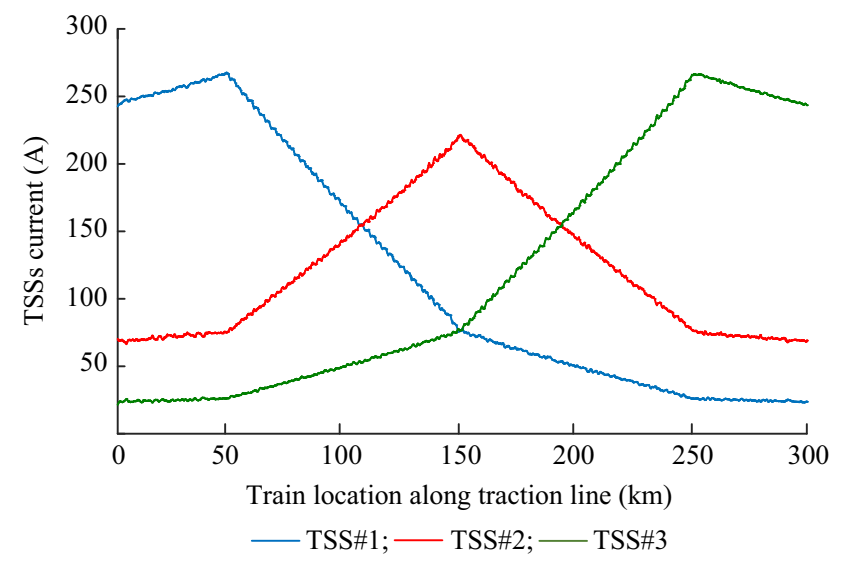

Fig. 4 Current-sharing behavior of TSSs by considering the journey of a train on a $300 \mathrm{~km}$ line, fed by three TSSs

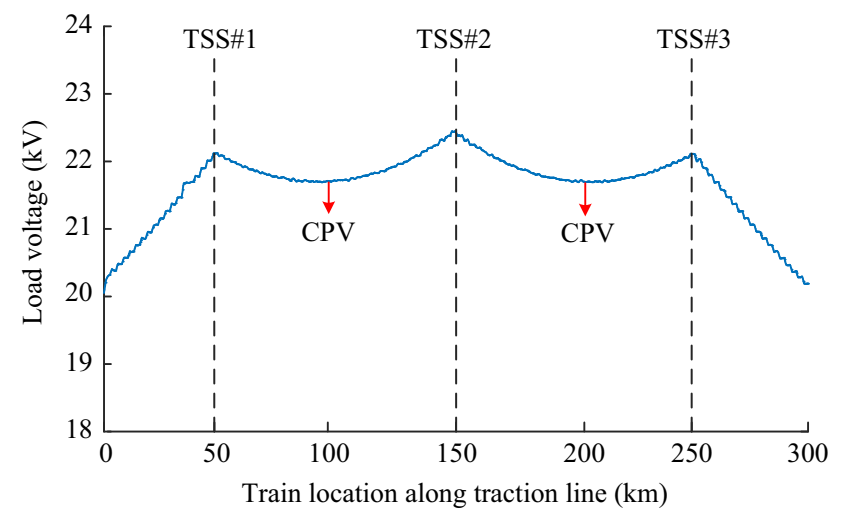

Fig. 5 Voltage deviation of catenary from rated value of $24 \mathrm{kV}$ owing to high droop values

$30 \mathrm{MW}$, rated voltage of $24 \mathrm{kV}$, and droop coefficient of 7 . Figure 4 shows how the better current-sharing among the TSSs have been degraded. A high droop value in the conventional droop method is also not exerting a considerable effect on the enhancement of current sharing.

In Fig. 5, the voltage profile exhibits a larger sag at the $\mathrm{CPV}$ locations as compared to the terminal positions of the TSSs. This is mainly because of the cumulative effect of the higher droop value and traction line resistance. This behavior of loading the TSSs near the load density is not suitable for renewable energy sources or for stiff, grid connected VSC TSSs. Although a further increase in the droop value of the conventional droop scheme improves the current sharing, it further degrades the catenary voltage at the TSSs terminals; moreover, its effect is more adverse at CPV. Better current-sharing can also be achieved by increasing the number of TSSs; however, it will incur higher expenses.

Several articles that are aimed at improving the droop control method for better operation of the conventional DC microgrids are available in the literature; these articles are discussed in the following subsection.

\subsection{Droop control schemes}

The equation for the conventional droop control scheme is expressed as (3). The difference between the reference voltage and output voltage is $R$ times the output current.

$V_{0}=V_{\text {ref }}-R I_{i}$

where $V_{\text {ref }}$ is the reference output voltage for which VSC TSS is designed; $V_{0}$ is the output voltage of the VSC TSS; $R$ is the droop value; $I_{i}$ is the output current of the VSC TSS. An increase in the droop value decreases the output voltage and hence decreases the output current of the TSS. The droop control as well as the voltage shifting term is discussed in [17, 18]; however, it considers the voltage regulation at the terminals of the VSC and is suitable for the conventional DC microgrids. The voltage regulation of VSC-based MVDC RES is discussed in [2, 11]; however, it does not provide an understanding of current sharing. An adaptive droop method is used in [19] by using the superimposed frequency to obtain the DC bus voltage information. However, the technique is not suitable for MVDC systems. The degree of acceleration coincidence of multiple trains has been minimized in [20] by utilizing the particle swamp algorithm. High droop gains and polynomial droop gains for DC microgrids are discussed in [21]. In [22], rather than the droop control, the Lagrange formulation is used to control HVDC light railway. Although numerous improved droop control schemes have been presented until the present for the average or proportional current-sharing, most of them are related to conventional DC microgrids. 


\section{Proposed adaptive droop scheme}

In this section, a control scheme for controlling VSC TSS is presented; the scheme is intended to enhance the current sharing as well as improve the catenary voltage by setting a minimum voltage threshold for the most critical voltage positions along the catenary. The system becomes a type of semi-distributed DC microgrid [23, 24], which depends on a reliable communication link for the exchange of information of currents from the other TSSs and CPV information from the midpoints between the substations. The layout of the system is shown in Fig. 6, whereas the basic control block is shown in Fig. 7. The information of the current generated by each TSS has to be shared with all the TSSs so that each TSS can have the information on the average current. Each TSS also obtains the voltage information of its adjacent CPV positions. The major portions of the proposed control scheme are explained in the preceding subsections.

\subsection{Average current}

For better current-sharing, the information on the currents produced by each TSS has to be shared with all the

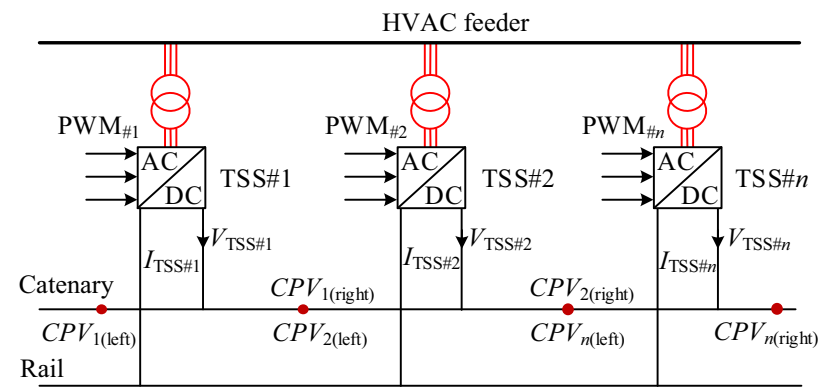

Fig. 6 Layout of catenary system
TSSs. The expression for the average current is provided in (4).

$I_{\mathrm{avg}}=\sum_{i=1}^{n} I_{\mathrm{TSS} \# i} / n$

where $I_{\mathrm{TSS} \# i}$ is the output current; $n$ is the number of TSSs.

\subsection{Exponential droop function}

The expression for the ratio of the output current to the average current is provided in (5); here, $u$ is the ratio of the TSS current to the average current. This sets the trend for the droop coefficient; if the ratio is equal to one, it implies that the TSS current is equal to the average current produced in the system, which is an ideal current-sharing scenario.

$u=I_{\mathrm{TSS} \# i} / I_{\mathrm{avg}}$

If the ratio $u$ is larger than one, it tends to increase the droop value, thus reducing the output voltage. If the ratio $u$ is less than one, it tends to reduce the droop value, thus increasing the output voltage. An exponential droop function is used to achieve a type of droop mechanism that offers small droop adjustments on smaller current deviations and large droop adjustments if the current deviations are large, as shown in Fig. 8. The proposed exponential function for the droop value is mathematically expressed as (6).

$R=\mathrm{e}^{u^{r}}-x$

where $R$ is the droop coefficient; $x$ is used for setting the base value (value at unity current-ratio) of droop; $r$ in the term $u^{r}$ is used to set the slope of the curve in Fig. 8. The higher the value of $r$, the higher is the slope of curve. Moreover, a larger $x$ will provide more space to the higher droop values and in turn adjust large deviations when the TSS current is larger than the average current. A higher

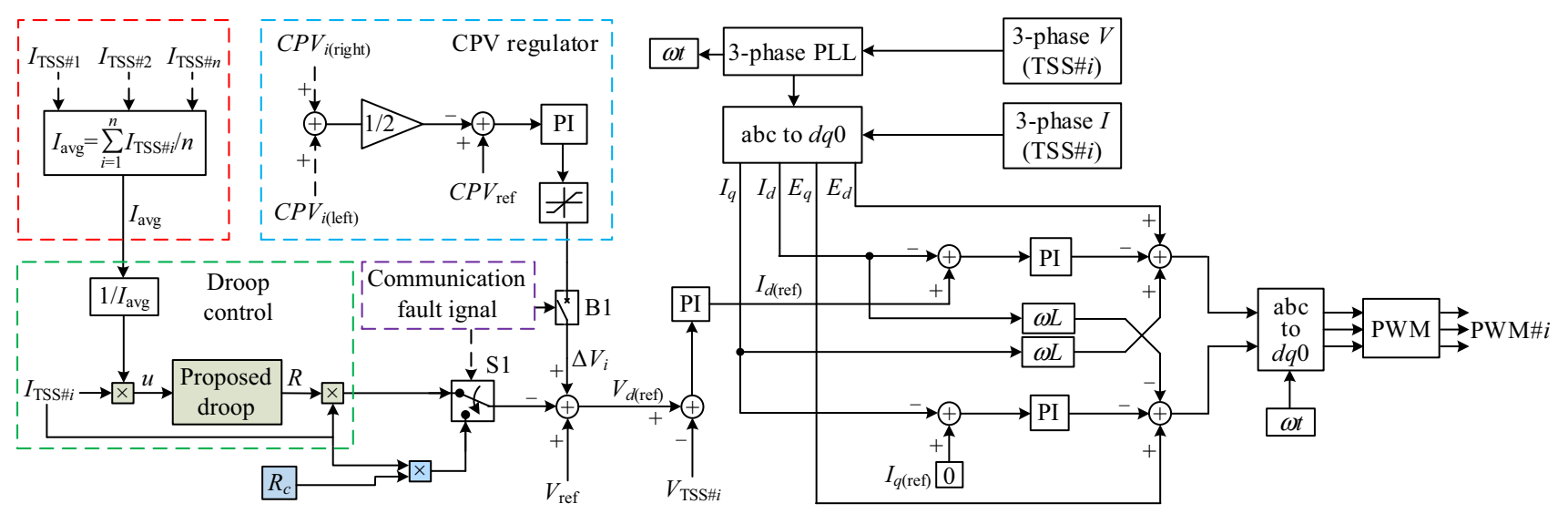

Fig. 7 Detailed control scheme for proposed control method 


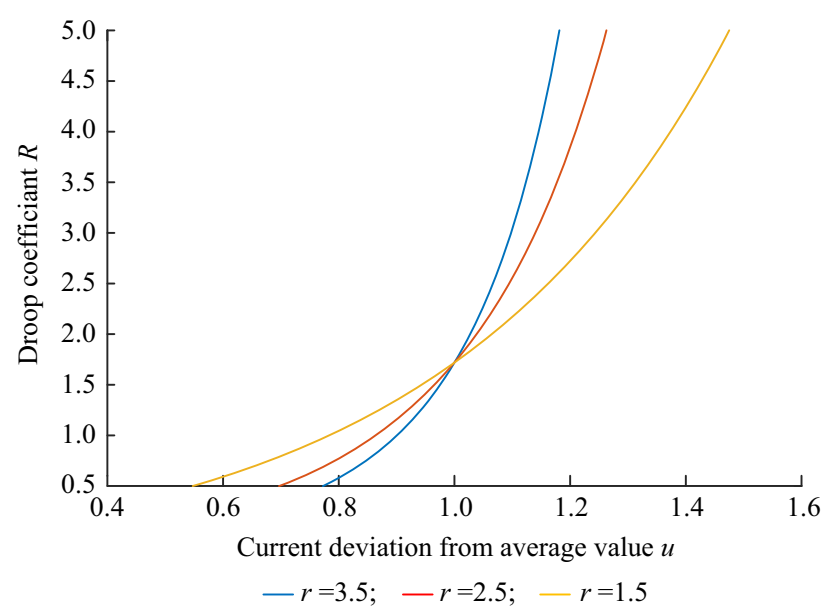

Fig. 8 Different curves of droop coefficient based on ratio of TSS current to average current $u$, expediting factor $r$ and variable for base value selector $x(x=1.0)$

$x$ also guarantees higher catenary voltages if the trains are equally spaced or near to equally spaced. A drawback of higher $x$ values is the lesser margin for droop gain below the base value, i.e., when the TSS current is less than the average current; this is not a matter of concern.

\subsection{CPV regulator}

To limit the effect of higher droop values on the output voltage, a CPV regulator is included in the control block. Each TSS receives the data on its adjacent left and right CPV locations and compares their average with a set reference $C P V_{\text {ref. }}$. Meanwhile, the limit block is used to ensure that only a positive value can pass through the regulator. The operation of the CPV regulator is mathematically expressed in (7); here, $\Delta V_{i}$ is the resultant voltage compensation or adjustment and has a positive value if the catenary voltage reduces below the minimum limit.

$\Delta V_{i}=\left(K_{p}+\frac{K_{i}}{s}\right)\left[C P V_{\text {ref }}-\frac{\left(C P V_{i(\text { left })}+C P V_{i(\text { right })}\right)}{2}\right]$

where $C P V_{\text {ref }}$ is the minimum allowable limit of the catenary voltage; $C P V_{i(\text { left })}$ and $C P V_{i \text { (right) }}$ are the $C P V$ values coming from the left and right sides of each TSS. If at any time during the operation, the droop value is increased to a level where it gets the CPV to the minimum limit (set in $C P V_{\text {ref }}$ ), the CPV regulator will clip the dip by adding the required $\Delta V_{i}$ adjustments to the system to eliminate the effects of the higher droop coefficients. $C P V_{\text {ref }}$ can be assumed to be between the rated value of $24 \mathrm{kV}$ and a minimum permissible value of $18 \mathrm{kV}(0.75$ p.u. of $24 \mathrm{kV})$. This is similar to the standard of 0.75 p.u. for $25 \mathrm{kV} \mathrm{AC}$ RES [2]. There is a trade-off between $C P V_{\text {ref }}$ and current sharing. A higher value of $C P V_{\text {ref }}$ within the operating range can ensure higher catenary voltages; however, it will result in reduced current-sharing among the sources. Similarly, a lower $C P V_{\text {ref }}$ within the operating range can reduce the catenary voltages; however, it will provide better current-sharing among the sources [17]. For the simulations in Section $5, C P V_{\text {ref }}$ is set as the mean value $(21 \mathrm{kV})$ within the operating range of an RES.

\subsection{Voltage and current control}

The droop action is completed by multiplying its value with the output current of the concerned TSS, and the resultant adjustments are added to the reference voltage as shown in Fig. 7. The CPV regulator contributes $\Delta V_{i}$ when the average of the CPV in the vicinity of a TSS reduces below $C P V_{\text {ref }}$. The overall equation for the reference voltage can be expressed as:

$V_{d(\text { ref })}=V_{\text {ref }}-R I_{\mathrm{TSS} \# i}+\Delta V$

where $V_{d \text { (ref) }}$ is the reference value provided to the system for the required adjustments in the output voltage; $V_{\text {ref }}$ is the reference set $(24 \mathrm{kV})$ for the traction system; $V_{\mathrm{TSS} \# i}$ is the output voltage of the concerned TSS. The error signal obtained by comparing $V_{d(\mathrm{ref})}$ and $V_{\mathrm{TSS} \# i}$ is passed to the PI controller. The output $I_{d(\text { ref })}$ serves as the reference current signal.

The stability analysis of the system for different time delays is described in Section 4. Apart from the communication delays, it is likely that the communication links for transmitting the information of the current from the other TSS or the communication link from CPV is completely lost. In this scenario, the primary objective will be to continue the normal operation of the trains uninterruptedly, rather than better current-sharing. To cater to such situation, the CPV regulator is disconnected from the control block through breaker $\mathrm{B} 1$, and the proposed droop scheme is switched to the conventional droop control method through switch S1, as shown in Fig. 7. The algorithm for controlling $\mathrm{S} 1$ and $\mathrm{B} 1$ in case of a communication fault signal is provided in Fig. 9.

In that case, the concerned TSS will use a constant droop value of $R_{c}$ [25]. The remaining TSSs will continue their operation according to the proposed scheme.

\section{Stability analysis}

The stability analysis of the system is performed by considering the train between the two substations TSS\#1 and TSS\#2 mentioned in Fig. 2. The parameters of the VSC TSS are listed in Table 2. The basic control structure of the VSC converter is provided in [26-28]. Considering 


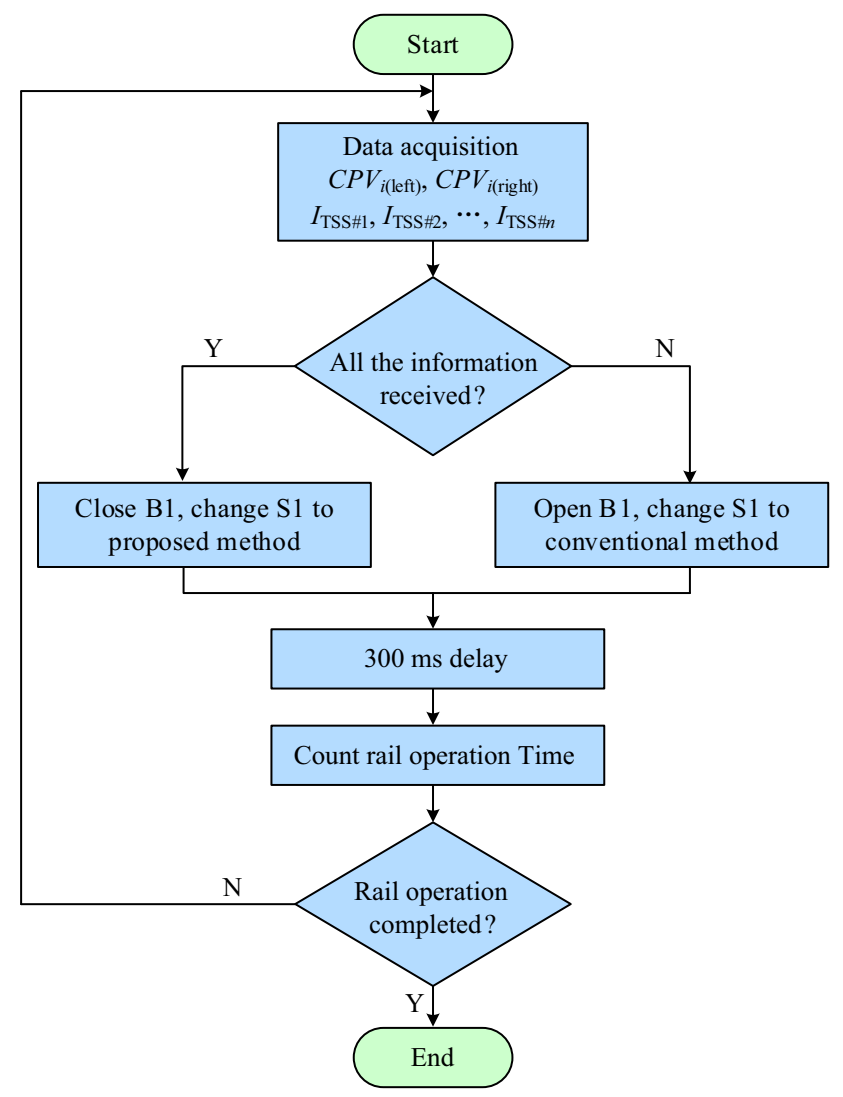

Fig. 9 Algorithm for controlling S1 and B1 in case of communication fault signal

Table 2 Specifications of system used in simulations

\begin{tabular}{ll}
\hline Category & Specifications \\
\hline Transformer & $220 \mathrm{kV} / 13.8 \mathrm{kV}$ \\
TSSs ratings & $24 \mathrm{kV}, 30 \mathrm{MW}$ \\
VSC topology & 3 -level \\
Line inductance, filter capacitance & $10 \mathrm{mH}, 4400 \mu \mathrm{F}$ \\
Traction line resistance $\left(R_{T}\right)$ & $0.1318 \Omega / \mathrm{km}$ \\
Resistance between two TSS & $11.33 \Omega$ \\
Train load (constant power load) & $8 \mathrm{MW}$ \\
Conventional scheme droop value & 4 \\
$r$ and $x$ for proposed droop control & $r=4, x=1$ \\
$C P V_{\text {ref }}$ for proposed control method & $21 \mathrm{kV}$ \\
\hline
\end{tabular}

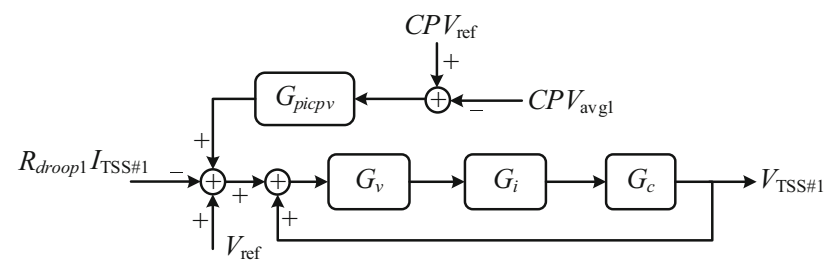

Fig. 10 Overall control block for obtaining transfer function of system the proposed modifications, the overall control block of the system is illustrated in Fig. 10.

The output voltage of a TSS can be obtained as:

$$
\begin{gathered}
V_{\mathrm{TSS} \# 1}=\left[V_{\mathrm{ref}}+\left(C P V_{\mathrm{ref}}-C P V_{\mathrm{avg} 1}\right) G_{d} G_{p i c p v}\right. \\
\left.-\left(R_{\text {droop } 1} I_{\mathrm{TSS} \# 1}\right) G_{d}\right] G_{c o n}
\end{gathered}
$$

where $G_{c o n}=G_{\nu} G_{i} G_{c} /\left(1+G_{\nu} G_{i} G_{c}\right), G_{c}=1 /(s C), G_{c o n}$ represents the voltage loop of the conventional VSC converter; $G_{v}, G_{i}$, and $G_{c}$ represent the voltage PI controller, current PI controller, and filtering capacitor, respectively. $G_{d}=1 /(1+T s)$ represents the delay, it is multiplied with the block output and is used as the cumulative delay including communication and processing; $G_{\text {picpv }}$ represents the PI controller at the CPV regulator. The relation for the output current of TSS\#1 can be obtained by applying KVL on the circuit illustrated in Fig. 2.

$I_{\mathrm{TSS} \# 1}=\frac{\left(R_{e q 2}+R_{L}\right) V_{\mathrm{TSS} \# 1}-V_{\mathrm{TSS} \# 2} R_{L}}{R_{e q 1} R_{e q 2}+R_{e q 1} R_{L}+R_{e q 2} R_{L}}$

where $R_{e q 1}=R_{\text {droop } 1}+R_{1}$ and $R_{\text {eq } 2}=R_{\text {droop } 2}+R_{2}$.

Considering $C P V_{\text {ref }}$ as $21 \mathrm{kV}$ (or $0.87 V_{\text {ref }}$ ), the overall transfer function can be obtained by substituting (10) in (9) as follows:

$\frac{V_{\mathrm{TSS} \# 1}}{V_{\mathrm{ref}}}=\frac{\left[\gamma+\gamma(0.87-A) G_{d} G_{\text {picpv }}-R_{\text {droop } 1} R_{\text {eq } 2} G_{d}\right] G_{\text {con }}}{\gamma+\gamma G_{\text {con }}}$

where $\quad \gamma=R_{e q 2} /\left(R_{e q 1} R_{e q 2}+R_{e q 1} R_{L}+R_{e q 2} R_{L}\right) \quad$ and $A=C P V_{\mathrm{avg}} / 24 \mathrm{kV}$.

For TSS\#1, the poles P1, P2, P3 and P4 are obtained from the transfer function of (11) and are mentioned in Fig. 11. Poles are evaluated for different time delays by considering the train to be at the midpoint between two substations. As the delay $T s$ varies from 0 to $0.3 \mathrm{~s}$, the poles shift toward the imaginary axis. This represents that

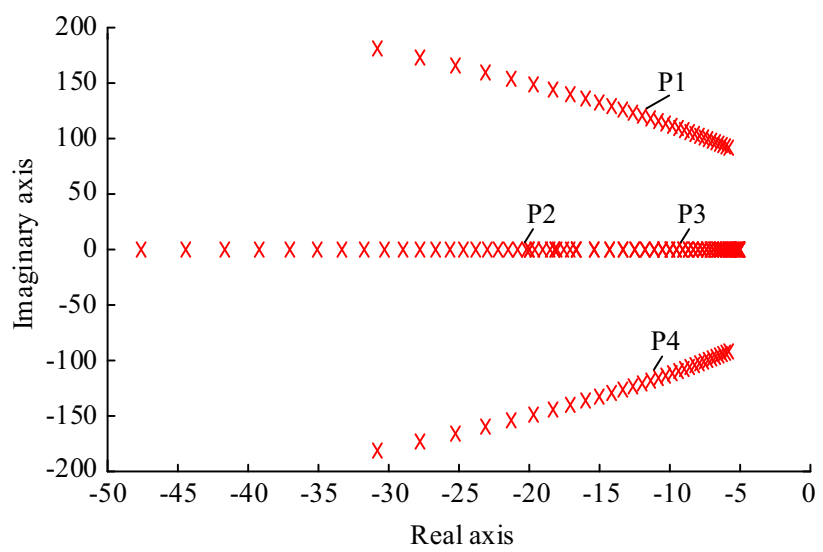

Fig. 11 Closed-loop poles at different time delays when the train is at the midpoint between two TSSs 


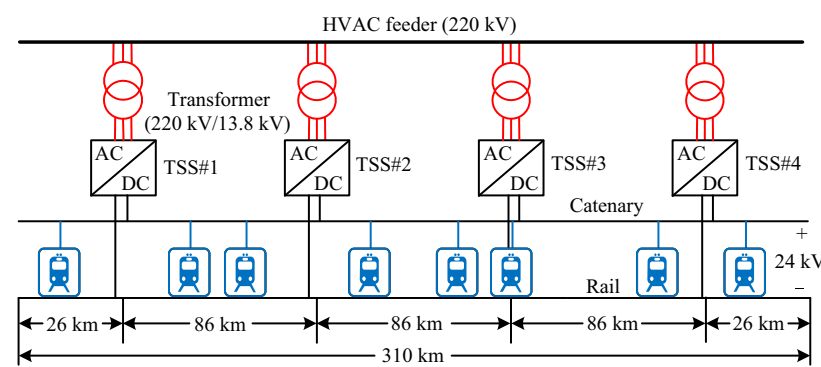

Fig. $12310 \mathrm{~km}$ high speed corridor from Chengdu to Chongqing considered for simulation

the system stability can be guaranteed for communication delays of up to $0.3 \mathrm{~s}$.

\section{Simulations for verifications}

In order to keep the simulations close to the actual traction system scenario, a $310 \mathrm{~km}$ high-speed corridor between Chengdu and Chongqing has been considered for simulations, as shown in Fig. 12. Considering the parameters of traction line resistance from Table 1, four TSSs have been considered for convenient operation, each with an output of $24 \mathrm{kV} \mathrm{DC}$, and at a distance of $86 \mathrm{~km}$ apart, while the 1st and 4th TSSs are supporting the end sections of $26 \mathrm{~km}$. Simulations are performed in MATLAB/Simulink. A $220 \mathrm{kV}$ HVAC feeder is used to fed TSSs, the current AC high speed corridors in China is utilizing the same feeder scheme. Eight trains are considered on the traction line. The specification of the system and VSC is given in Table 2.

Simulations are performed for equally spaced trains, unequally spaced trains, and a single moving train under both the conventional droop method and proposed improved droop method.

\subsection{Equally spaced trains}

As discussed earlier, equally spaced trains w.r.t TSSs is not a practical scenario. The case is examined only to illustrate the effectiveness of the proposed method w.r.t the conventional droop. For this purpose, simulations have been performed on the selected Chengdu to Chongqing high-speed corridor. The resultant voltage and current profiles are mentioned in Figs. 13 and 14. Owing to the lower droop gain in the proposed method, the catenary voltages are comparatively high. This is because of the low droop coefficients arising from the exponential droop function owing to the lesser difference between the TSS current and average current. In contrast, the conventional droop method uses a fixed droop value, which results in lower catenary voltages even if the trains are equally

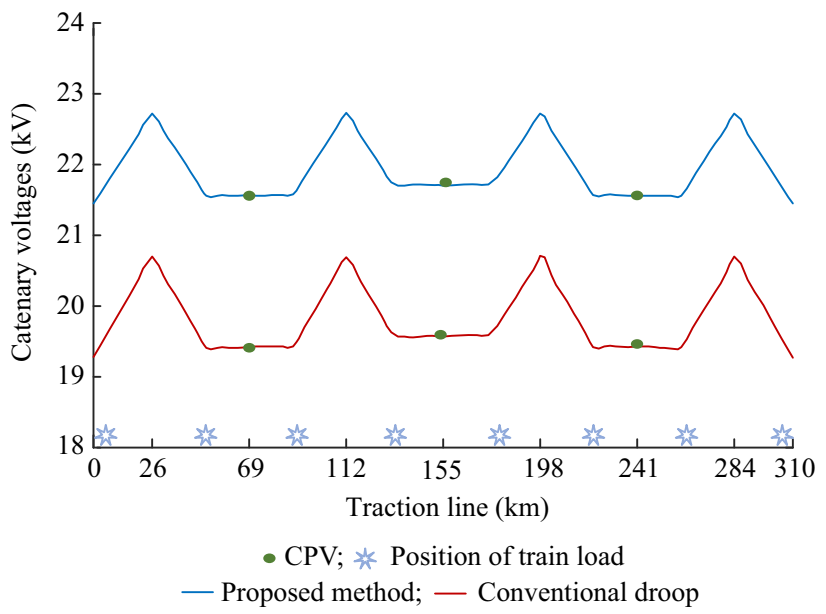

Fig. 13 Comparison of catenary voltages under conventional droop method with proposed droop method when trains are equally spaced

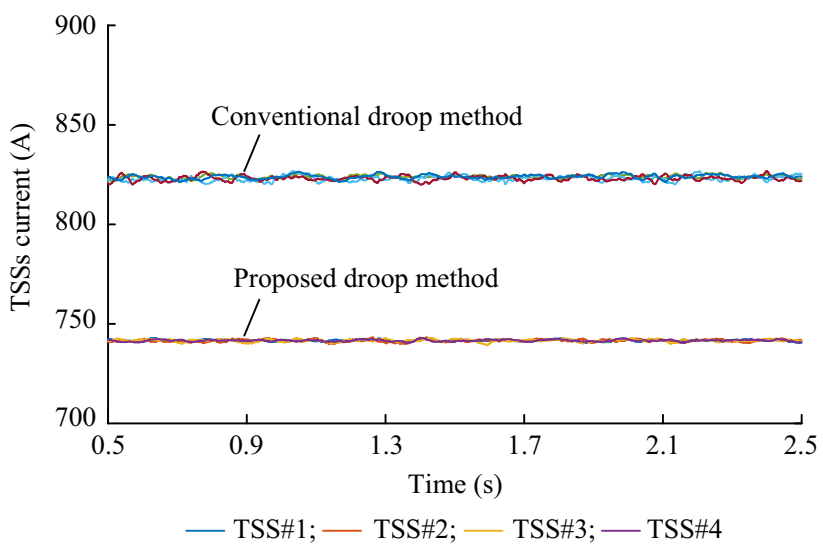

Fig. 14 Comparison of TSS currents when trains are equally spaced

spaced. The TSS currents overlap and have approximately equal values. That is because each TSS has the train loads at equal distances, and hence, each TSS encounter an identical resistance between its terminals and load. It can also be observed that the average current in the case of the conventional droop method is $823 \mathrm{~A}$; this is higher than the average current of $741 \mathrm{~A}$ in the case of the proposed droop control method. This is mainly because of the higher terminal voltage obtained through the proposed droop method.

\subsection{Unequally spaced trains}

The simulations for unequally spaced trains are conducted on the considered traction line, as shown in Fig. 12. The unequally spaced trains pose a significant challenge while considering the control of MVDC RES. The catenary voltages in the case of the proposed droop control method are high as compared to the conventional droop, as shown 


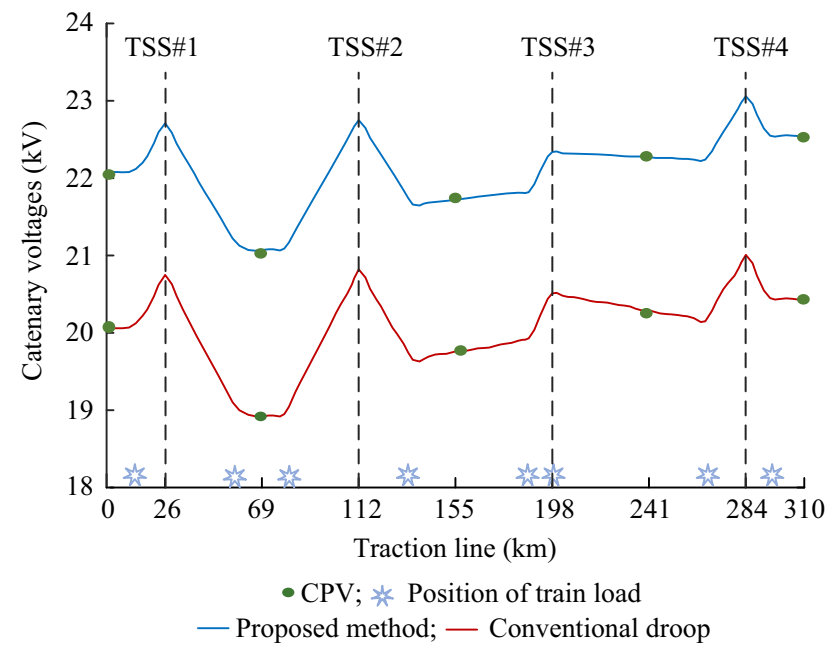

Fig. 15 Catenary voltages in terms of proposed droop method and conventional droop method

in Fig. 15. The CPV positions are highlighted with green dots.

The maximum and minimum voltages in the case of the proposed droop control method are $23.06 \mathrm{kV}$ and $21.07 \mathrm{kV}$, respectively, with an average voltage of approximately $22.28 \mathrm{kV}$. Meanwhile in the case of the conventional droop control method, the maximum and minimum voltages are $21 \mathrm{kV}$ and $18.9 \mathrm{kV}$, respectively, with an average voltage of $20.27 \mathrm{kV}$. The simulation results of current-sharing in the case of the conventional droop are shown in Fig. 16. The current sharing has been improved through conventional droop control; however, the difference between the maximum and minimum currents is still large. Moreover, the average current is increased to $805 \mathrm{~A}$, which implies higher line losses.

The simulation results of the currents generated by the TSSs in the case of the proposed method are shown in Fig. 17. The results reveal that the difference between the maximum and minimum currents is significantly less as compared to that of the conventional droop, with an average current of $736 \mathrm{~A}$. This implies less line losses as compared to those of the conventional droop. Hence, it can be concluded that the proposed control method can realize better current-sharing in conjunction with higher catenary voltages and increased efficiency.

\subsection{Moving train case}

For better analysis and comparison of the two methods, the simulations are performed for a single moving train by considering two substations from Fig. 12, for example TSS\#1 and TSS\#2, $86 \mathrm{~km}$ apart from each other. The CPV voltage, rather than the catenary voltage, is measured by considering a voltmeter at the midpoint between the two

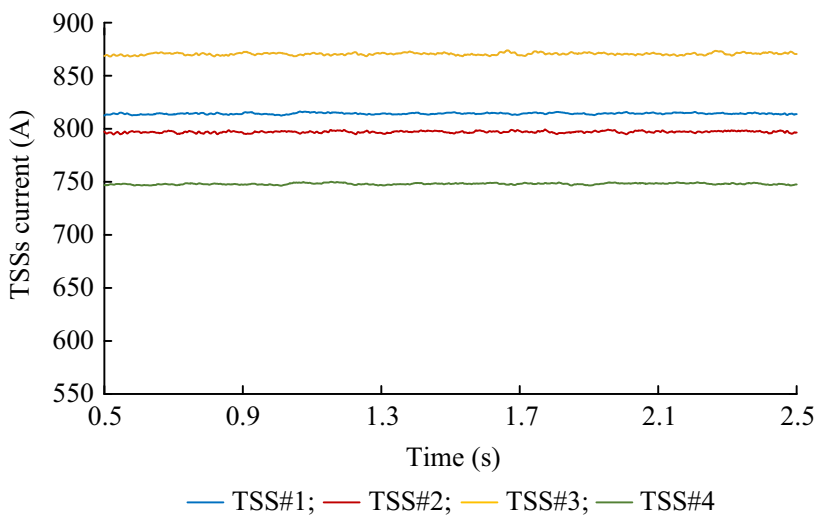

Fig. 16 TSSs currents when conventional droop method is utilized

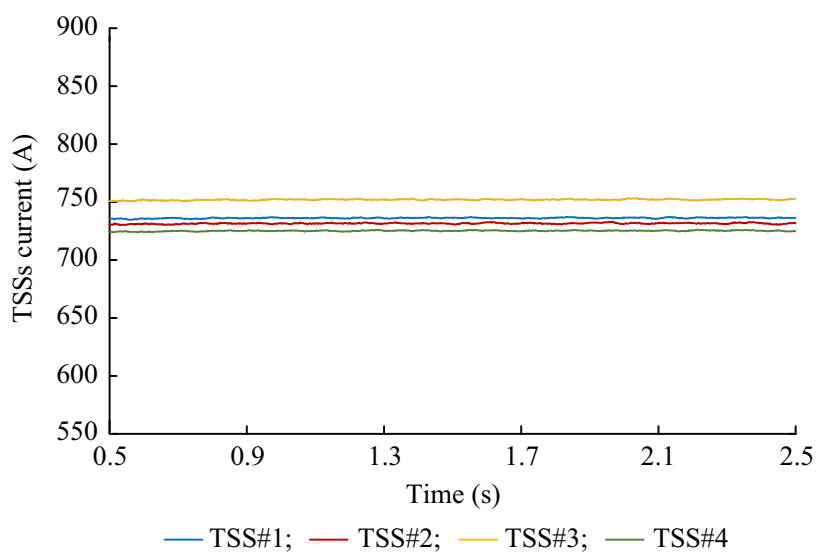

Fig. 17 TSSs currents when the proposed droop method is utilized

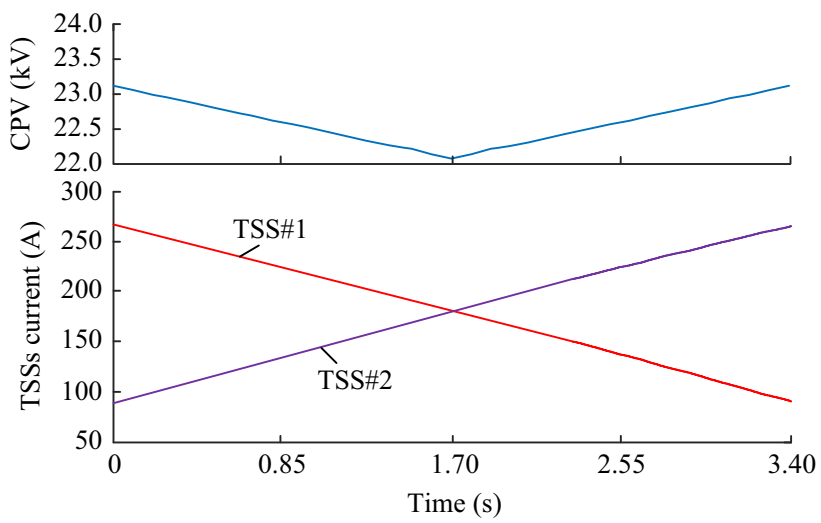

Fig. 18 Current sharing and CPV through conventional droop when a single train moves from TSS\#1 to TSS\#2

substations. The specifications of the conventional droop, proposed droop, and traction line are similar, as illustrated in Table 2. Figure 18 shows the current-sharing and CPV voltage in the case of the conventional droop. It can be observed that the maximum and minimum currents generated by each TSS ranges from a maximum of $270 \mathrm{~A}$ to a 


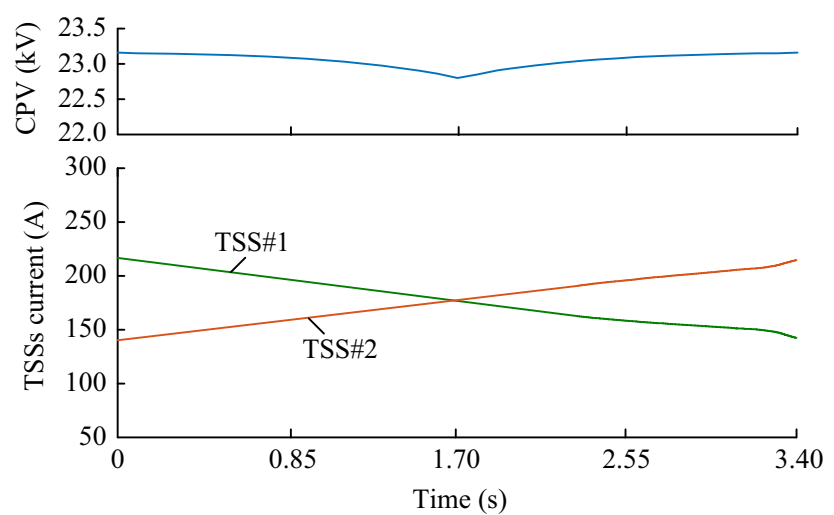

Fig. 19 Current sharing and CPV through the proposed droop when a train moves from TSS\#1 to TSS\#2

minimum of $90 \mathrm{~A}$, whereas the CPV voltage varies between 23.12 and $22.06 \mathrm{kV}$.

Figure 19 shows the results for the proposed method. In this case, the TSS currents vary between 220 and $140 \mathrm{~A}$. The current sharing in the proposed method is improved because it uses varying droop values by considering the currents generated by each TSS, whereas the conventional droop method uses a fixed droop value throughout the train journey. The minimum value of the CPV voltage in case of the proposed method goes down to $22.80 \mathrm{kV}$, which is higher than that for the conventional method.

This is mainly because when the train approaches the midpoint between the two substations, the difference between the currents decreases. Hence, the proposed method reduces the value of the droops accordingly.

\section{Experiments for verification}

To more effectively validate the effectiveness of the proposed control method, an experimental setup consisting of two prototype TSSs is constructed. The layout and photographic image of the experimental setup are illustrated in Figs. 20 and 21, respectively.

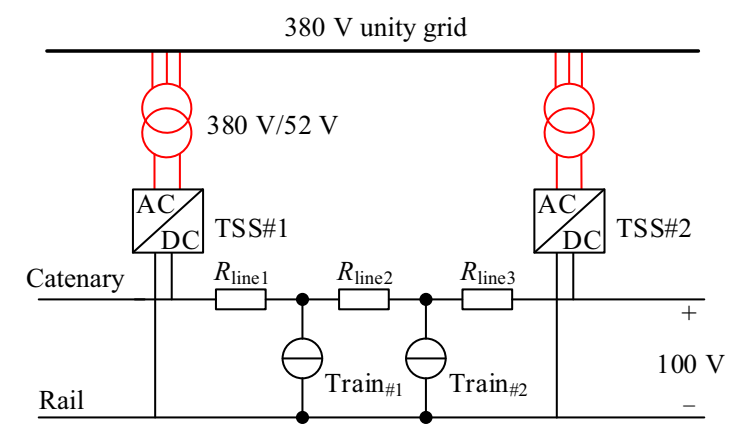

Fig. 20 Configuration of experimental setup with two TSSs

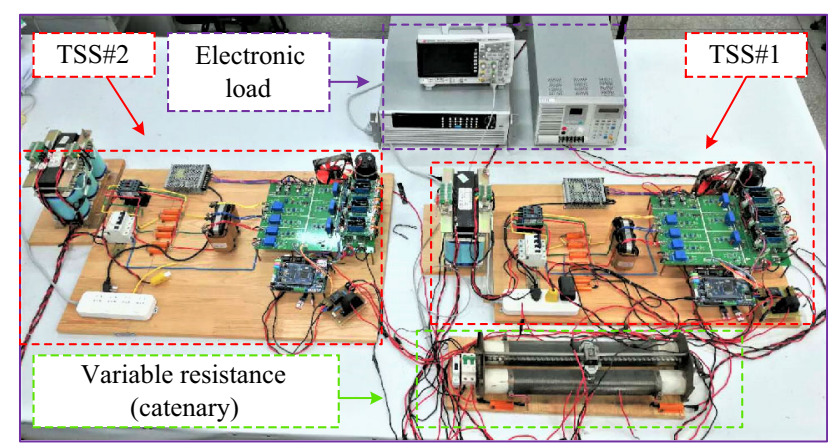

Fig. 21 Experimental setup used in tests

Table 3 Specifications of system used in experiments

\begin{tabular}{ll}
\hline Category & Specifications \\
\hline Transformer & $380 \mathrm{~V} / 52 \mathrm{~V}, 1500 \mathrm{VA}$ \\
VSC, TSSs ratings & $100 \mathrm{~V}, 500 \mathrm{~W}$ \\
VSC topology & $2-$ level \\
Line inductance, filter capacitance & $10 \mathrm{mH}, 2200 \mu \mathrm{F}$ \\
Total traction line resistance $\left(R_{T}\right)$ & $7 \Omega$ \\
Train load (constant power load) & $200 \mathrm{~W} /$ each \\
Conventional droop control & 4 \\
$r$ and $x$ for proposed droop control & $r=4, x=1$ \\
$C P V_{\text {ref }}$ for proposed control method & $90 \mathrm{~V}$ \\
\hline
\end{tabular}

The specifications of the system are listed in Table 3. The experiments are performed for unequally spaced trains and a moving train.

\subsection{Unequally spaced trains}

The current-sharing behavior of two unequally spaced trains, each having a constant power load of $200 \mathrm{~W}$, are illustrated in Fig. 22a, b for the conventional droop control method and proposed droop control method, respectively. As both the trains are closer to TSS\#1 as compared to TSS\#2, the loads attempt to drag more current from TSS\#1 owing to the lesser traction line resistance. The catenary voltages for both the methods for unequally spaced trains are shown in Fig. 22c.

The results reveal a better current-sharing under the proposed droop control method when the trains are unequally spaced, in conjunction with an increased efficiency owing to the higher catenary voltages.

\subsection{Moving train}

Furthermore, to verify the effectiveness of the proposed method, a scenario of a $300 \mathrm{~W}$ train moving form TSS\#1 to 


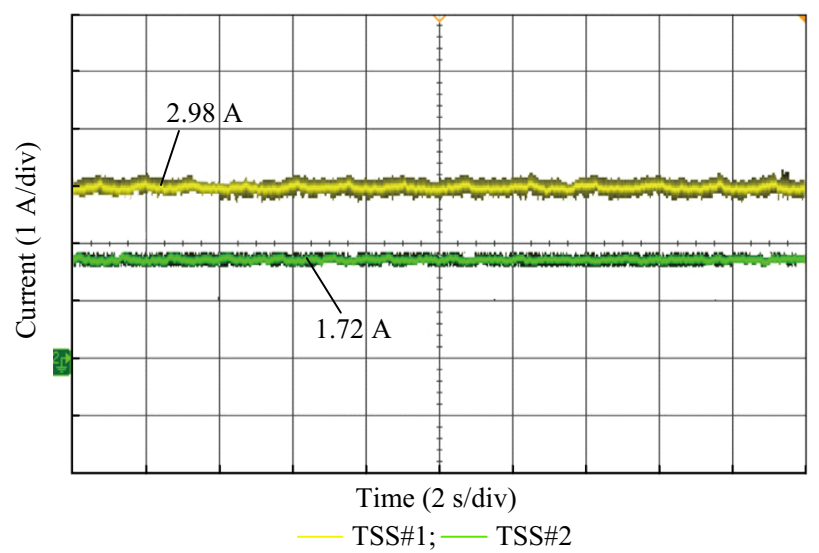

(a) Current-sharing under conventional droop control

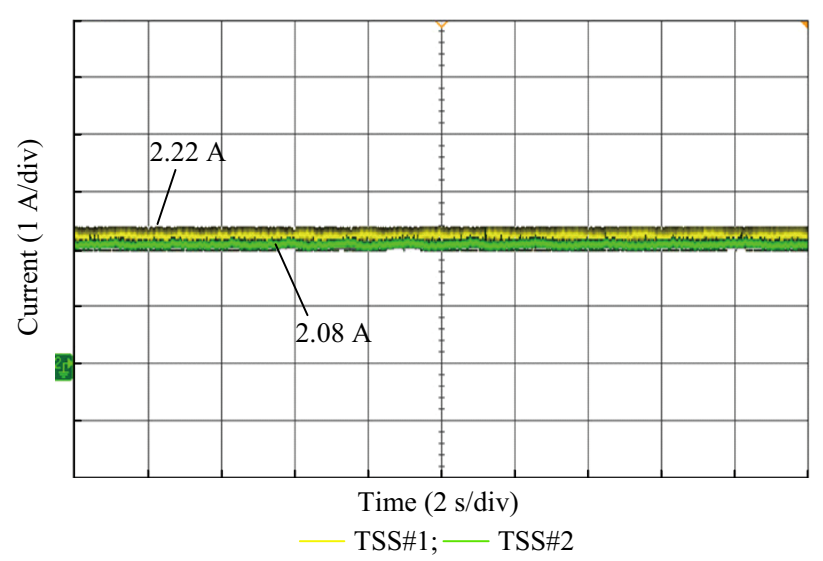

(b) Current-sharing under proposed control

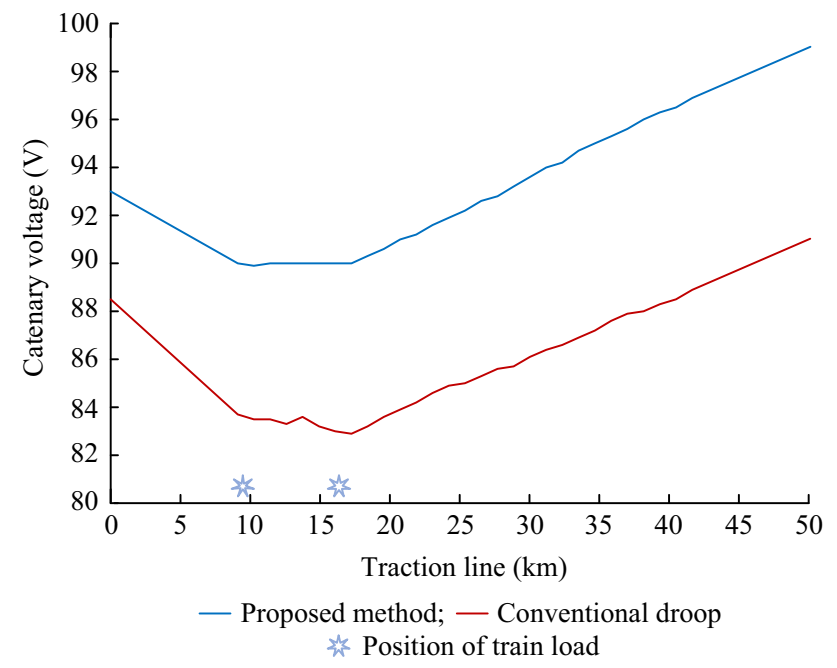

(c) Catenary voltages under conventional droop control and proposed control

Fig. 22 Experimental results when trains are unequally spaced

TSS\#2 is tested through experiment, and the results of current sharing for the conventional droop and proposed droop schemes are provided in Figs. 23 and 24, respectively. Only the CPV of the two methods, rather than the

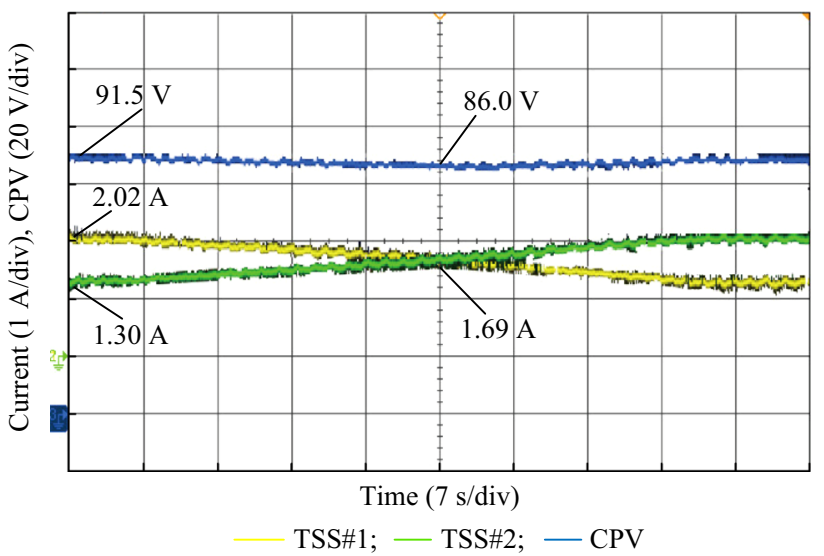

Fig. 23 Current sharing and CPV through conventional droop when a train moves from TSS\#1 to TSS\#2

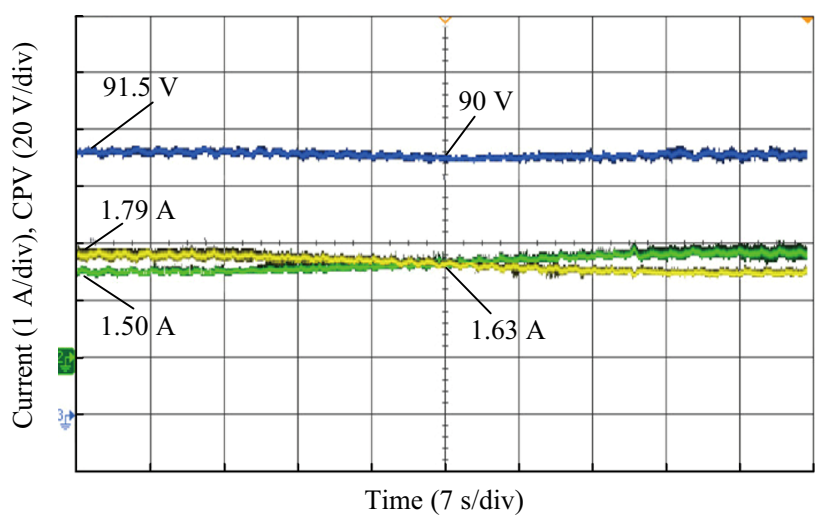

TSS\#1; - TSS\#2; - CPV

Fig. 24 Current sharing and CPV through proposed droop when a train moves from TSS\#1 to TSS\#2

catenary voltage, are mentioned in their respective graphs. The experiment results under the proposed droop control method reveal a better current-sharing in conjunction with higher CPV ranging from 91.5 to $90 \mathrm{~V}$. Hence, the proposed control method provides better current sharing as well as minimizes the losses.

\section{Conclusion}

This paper provides a modified droop control scheme for the VSC-based MVDC RES, with an objective of obtaining better current-sharing among the TSSs in conjunction with acceptable catenary voltages. Better current-sharing has been achieved with lower droop values through the proposed method, as compared to the conventional droop. Moreover, the catenary voltages are maintained above the minimum permissible limits through a $\mathrm{CPV}$ regulator. The proposed techniques are verified through both simulations and experiments. A rapid and reliable communication link 
is one of the necessary requirements for the operation of such systems; this will be addressed in future, together with an energy management system for MVDC RES.

Acknowledgements This work was partly supported by "the Open Project of National Rail Transit Electrification and Automation Engineering Technique Research Center" (No. NEEC-2017-A03), and partly supported by "the Fundamental Research Funds for the Central Universities” (No. 2682017CX041).

Open Access This article is distributed under the terms of the Creative Commons Attribution 4.0 International License (http:// creativecommons.org/licenses/by/4.0/), which permits unrestricted use, distribution, and reproduction in any medium, provided you give appropriate credit to the original author(s) and the source, provide a link to the Creative Commons license, and indicate if changes were made.

\section{References}

[1] Tan D (2016) Transportation electrification: challenges and opportunities. IEEE Power Electron Mag 3(2):50-52

[2] Gómez-Expósito A, Mauricio JM, Maza-Ortega JM (2014) VSC-based MVDC railway electrification system. IEEE Trans Power Deliv 29(1):422-431

[3] Gazafrudi SMM, Langerudy AT, Fuchs EF et al (2015) Power quality issues in railway electrification: a comprehensive perspective. IEEE Trans Ind Electron 62(5):3081-3090

[4] $\mathrm{Hu} \mathrm{H}, \mathrm{He} \mathrm{Z,} \mathrm{Li} \mathrm{X} \mathrm{et} \mathrm{al} \mathrm{(2016)} \mathrm{Power-quality} \mathrm{impact} \mathrm{assessment}$ for high-speed railway associated with high-speed trains using train timetable part I: methodology and modeling. IEEE Trans Power Deliv 31(2):693-703

[5] Gavriluta C, Candela JI, Citro C et al (2014) Decentralized primary control of MTDC networks with energy storage and distributed generation. IEEE Trans Ind Appl 50(6):4122-4131

[6] An T, Tang G, Wang W (2017) Research and application on multi-terminal and DC grids based on VSC-HVDC technology in China. High Volt 2(1):1-10

[7] Fabre J, Ladoux P, Piton M (2015) Characterization and implementation of dual-SiC MOSFET modules for future use in traction converters. IEEE Trans Power Electron 30(8):4079-4090

[8] Fabre J, Ladoux P, Solano E et al (2017) MVDC three-wire supply systems for electric railways: design and test of a full $\mathrm{SiC}$ multilevel chopper. IEEE Trans Ind Appl 53(6):5820-5830

[9] Ladoux P, Blaquiere JM, Caron H et al (2015) New three-wire supply systems for DC electric railways. IET Electr Syst Transp 5(3): 112-119

[10] Östlund S (2014) Rail power supplies going more power electronic. IEEE Electr Mag 2(3):4-60

[11] Yang X, Hu H, Ge Y et al (2018) An improved droop control strategy for VSC-based MVDC traction power supply system. IEEE Trans Ind Appl 54(5):5173-5186

[12] Abrahamsson L, Kjellqvist T, Ostlund S (2012) High-voltage DC-feeder solution for electric railways. IET Power Electron 5(9): $1776-1784$

[13] Steimel A (2012) Under Europe's incompatible catenary voltages a review of multi-system traction technology. In: Proceedings of electrical systems for aircraft, railway and ship propulsion, Bologna, Italy, 16-18 October 2012, 8 pp
[14] Arboleya P, Bidaguren P, Armendariz U (2016) Energy is on board: energy storage and other alternatives in modern light railways. IEEE Electr Mag 4(3):30-41

[15] Khayyam S, Ponci F, Goikoetxea J et al (2016) Railway energy management system: centralized-decentralized automation architecture. IEEE Trans Smart Grid 7(2):1164-1175

[16] Tian Z, Hillmansen S, Roberts C et al (2016) Energy evaluation of the power network of a DC railway system with regenerating trains. IET Electr Syst Transp 6(2):41-49

[17] Guerrero JM, Vásquez JC, Teodorescu R (2009) Hierarchical control of droop-controlled DC and AC microgrids-a general approach towards standardization. In: Proceedings of 35 th annual conference of IEEE industrial electronics, Porto, Portugal, 3-5 November 2009, 6 pp

[18] Lu X, Guerrero JM, Sun K et al (2014) An improved droop control method for DC microgrids based on low bandwidth communication with DC bus voltage restoration and enhanced current sharing accuracy. IEEE Trans Power Electron 29(4):1800-1812

[19] Peyghami S, Mokhtari H, Blaabjerg F (2017) Decentralized load sharing in a low-voltage direct current microgrid with an adaptive droop approach based on a superimposed frequency. IEEE J Emerg Sel Top Power Electron 5(3):1205-1215

[20] Li G, Du G, Wang C (2016) Optimisation of total traction current based on niche improved particle swarm algorithms. IET Electr Syst Transp 6(4):253-260

[21] Prabhakaran P, Goyal Y, Agarwal V (2018) Novel nonlinear droop control techniques to overcome the load sharing and voltage regulation issues in DC microgrid. IEEE Trans Power Electron 33(5):4477-4487

[22] Vial R, Riu D, Retière N (2010) Simulating calculations and optimization design of a new HVDC supply power for light rail system. In: Proceedings of annual conference on IEEE industrial electronics society, Glendale, USA, 7-10 November 2010, 6 pp

[23] Dou CX, Liu B (2013) Multi-agent based hierarchical hybrid control for smart microgrid. IEEE Trans Smart Grid 4(2):771-778

[24] Nunna HSVSK, Doolla S (2013) Multiagent-based distributedenergy-resource management for intelligent microgrids. IEEE Trans Ind Electron 60(4):1678-1687

[25] Cingoz F, Elrayyah A, Sozer Y (2017) Optimized settings of droop parameters using stochastic load modeling for effective DC microgrids operation. IEEE Trans Ind Appl 53(2):1358-1371

[26] Wang C, Li X, Guo L et al (2014) A nonlinear-disturbanceobserver-based DC-bus voltage control for a hybrid AC/DC microgrid. IEEE Trans Power Electron 29(11):6162-6177

[27] Sanjuan SL (2010) Voltage oriented control of three-phase boost PWM converters. Dissertation, Chalmers University of Technology

[28] $\mathrm{Hu} \mathrm{H}$, Tao H, Blaabjerg F et al (2018) Train-network interactions and stability evaluation in high-speed railways-part I: phenomena and modeling. IEEE Trans Power Electron 33(6):4627-4642

Salman AATIF received the Bachelor and Master's degrees in Electrical Engineering from University of Engineering and Technology (UET) Peshawar, Pakistan, in 2008 and 2014 respectively. From 2008 to 2015 he remains lecturer at UET Peshawar. Currently he is perusing his $\mathrm{Ph} . \mathrm{D}$. degree from Southwest Jiaotong University, Chengdu, China. His research interests include integration of renewable energies and energy storage devices in MVDC railways. 
Haitao HU received the B.S. degree from Zhengzhou University, Zhengzhou, China, in 2010, and the Ph.D. degree from Southwest Jiaotong University, Chengdu, China, in 2014, all in Electrical Engineering. From 2013 to 2014, He worked as a visiting doctoral scholar at University of Alberta, Edmonton, Canada. Currently, he is an Associate Professor with School of Electrical Engineering at Southwest Jiaotong University. His main research interests are power quality and stability of the electric traction system.

Xiaowei YANG received the B.S. degree in Electrical Engineering from Southwest Jiaotong University, China, in 2016. Currently, he is pursuing the Ph.D. degree in Electrical Engineering at Southwest Jiaotong University. His research interests include modeling and control, integration of renewable energy source and energy storage systems, and energy management strategy of DC traction power supply system.

Yinbo GE received the B.S. degree in Electrical Engineering from Southwest Jiaotong University, China, in 2017. Currently, he is pursuing the M.Sc. degree in Electrical Engineering at Southwest Jiaotong University, Chengdu, China. His main research interests are DC traction power supply system modeling and control.

Zhengyou HE received the B.Sc. degree and M.Sc. degree in Computational Mechanics from Chongqing University, Chongqing, China, in 1992 and 1995, respectively. He received the Ph.D. degree in the School of Electrical Engineering from Southwest Jiaotong University, Chengdu, China, in 2001. Currently, he is a Professor in the School of Electrical Engineering at Southwest Jiaotong University. His research interests include signal process and information theory applied to electrical power system, and application of wavelet transforms in power system.

Shibin GAO received B.S degree, M.S. degree and Ph.D. degree in Electrical Engineering from Southwest Jiaotong University, China, 1986, 1999, 2006, respectively. Currently, he is a Professor in Southwest Jiaotong University. His research interests are protection and control of electric traction system. 